\title{
Types, frequencies and value of intra-varietal genotypic non-uniformity in common wheat cultivars: Authentic biotypes and foreign seeds
}

\author{
Eugene Metakovsky ${ }^{\mathrm{a}}$, Viktor Melnik ${ }^{\mathrm{b}}$, Laura Pascual $^{\mathrm{a}}$, Georgy A. Romanov ${ }^{\mathrm{c}}$, Colin W. Wrigley ${ }^{\mathrm{d}, *}$ \\ ${ }^{a}$ Unit of Genetics, Department of Biotechnology, Plant Biology, Universidad Politecnica de Madrid, Madrid, 28040, Spain \\ ${ }^{\mathrm{b}}$ N.I.Vavilov Institute of General Genetics RAS, Moscow, 117971, Russia \\ ${ }^{\mathrm{c}}$ K.A.Timiryazev Institute of Plant Physiology RAS, Moscow, 127276, Russia \\ ${ }^{\mathrm{d}}$ QAAFI, University of Queensland, Brisbane, QLD 4072 Australia
}

A R T I C L E IN F O

\section{Keywords:}

Gliadin alleles in Triticum aestivum

Admixtures in registered cultivars

Authentic biotypes

Dough quality

\begin{abstract}
A B S T R A C T
Seed-by-seed electrophoretic analysis of the seed storage-protein gliadin was used to identify two major types of intra-varietal non-uniformity in grain samples of 756 registered Triticum aestivum cultivars: authentic biotypes (genotypes arising from the original cross performed by the breeder) and foreign seeds (admixed alien genotypes or products of accidental cross-pollination). Authentic biotypes of a cultivar, distinct in alleles at one or more of eight Gli loci (Gli-1, Gli-2, Gli-A3, Gli-B3), occurred in more than 30\% of the cultivars studied. Four biotypes of the cultivar Saratovskaya-29 (distinct in alleles at the Gli-A1 and Gli-A2 loci) differed significantly in 1000-kernel mass and dough quality. The relative frequency of biotypes changed with time when the cultivar grew in the region where it was bred and, more strongly, in alien regions. There is thus potential value in characterizing multiple biotypes to facilitate the adaptation of a cultivar to given eco-climatic environments. Changes in the frequencies of biotypes alter the grain quality of a cultivar as a whole. Ignorance of possible wheat intra-varietal non-uniformity (biotypes and foreign genotypes) in a grain material may confuse the interpretation of experimental results in field trails and grain-quality assessments.
\end{abstract}

\section{Introduction}

To be officially registered as a cultivar, each newly-bred wheat genotype must pass a series of tests to confirm that it fits to three main requirements (rules of DUS): it must be Distinct (different from other cultivars), Uniform (represent only one genotype), and Stable (not segregate or change in any other way). The DUS procedure provides a basis for protecting the intellectual property of the breeder for a given cultivar (Cooke, 1995; Law et al., 1998; Cooke and Wrigley, 2004; Uthayakumaran et al., 2006). To confirm the uniformity (and to reveal, if present, intra-varietal non-uniformity), any polymorphic genetic markers, for example, gliadin composition, may be successfully applied.

The electrophoregram of gliadin composition is specific for the genotype of a wheat cultivar and does not depend on the growing conditions of the plant that produced that seed. All gliadin bands in an electrophoregram are controlled, in hexaploid wheat, by six major Gli loci (Gli-A1, Gli-B1, Gli-D1, Gli-A2, Gli-B2, Gli-D2) and by at least five minor ones (Gli-A3, Gli-A5, Gli-A6, Gli-B3, and Gli-B5) (reviewed in Metakovsky, 2015). There is vast multiple allelism at Gli loci; a recent catalogue includes from 16 to 49 alleles at each of the major loci
(Metakovsky et al., 2018), and two to four alleles at a minor one (Metakovsky et al., 1996). Each allele at a major Gli locus controls the synthesis of two or more gliadin electrophoretic bands (a block of bands) inherited together. Blocks controlled by alleles at the same locus differ by the number and electrophoretic mobility of their bands (Sozinov and Poperelya, 1980; Sobko and Poperelya, 1986). Due to the multiple allelism, there has been no case of two unrelated cultivars having identical gliadin electrophoregrams in studies of more than 1000 cultivars (Metakovsky et al., 2018).

Seed-by-seed analysis of a grain sample is exclusively valuable for disclosing various types of intra-varietal non-uniformity of genotype. It was discovered long ago that, in spite of DUS rules, individual seeds of the same cultivar might differ in their gliadin electrophoregrams (for example, Wrigley and Shepherd, 1974). Earlier, all differences discovered electrophoretically between seeds of the same cultivar were considered as "biotypes", especially if the off-type seed was morphologically identical to the main type of the cultivar (Appleyard et al., 1979; Pogna et al., 1982; Wrigley et al., 1982). Application of the knowledge of gliadin genetics to electrophoregrams permits distinctions to be made between authentic biotypes of a cultivar versus

\footnotetext{
* Corresponding author. 2 Duncan Place, Epping, NSW, 2121, Australia.

E-mail addresses: C.Wrigley1@uq.edu.au, colinwrigley@iinet.net.au (C.W. Wrigley).
} 


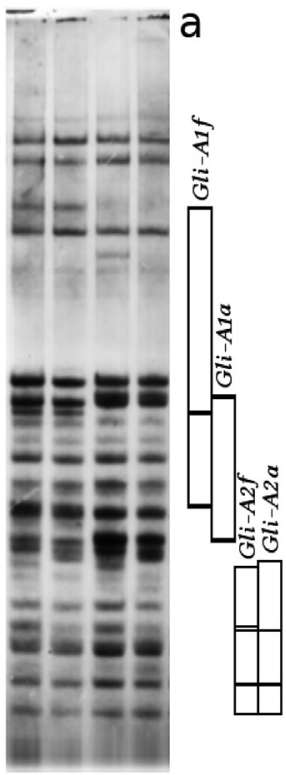

$\begin{array}{llll}1 & 2 & 3 & 4\end{array}$

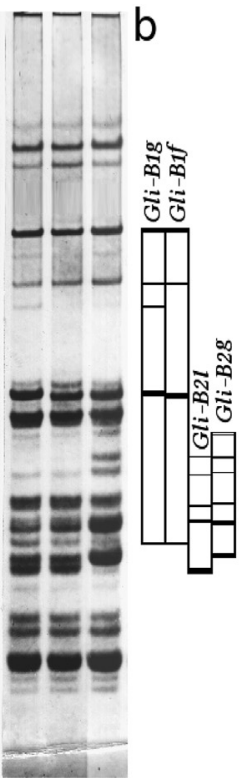

123

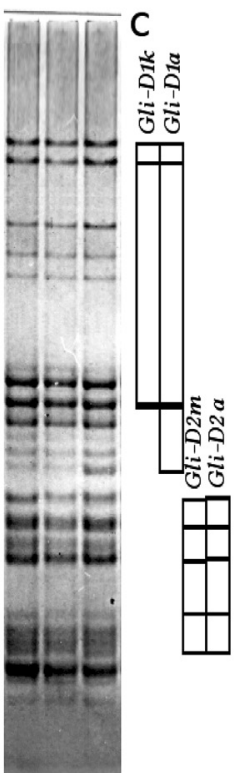

123

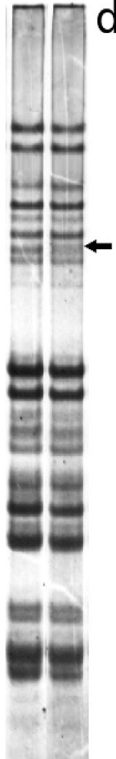

12

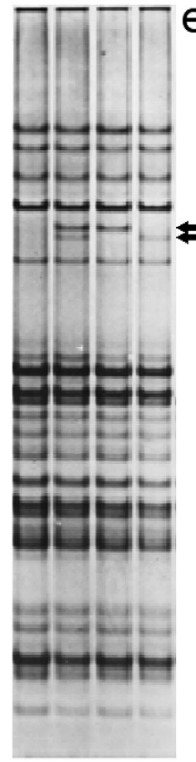

$\begin{array}{llll}1 & 2 & 3 & 4\end{array}$
Fig. 1. Gliadin electrophoregrams of biotypes of some non-uniform cultivars. a, Egret (Australia) lanes 1, 2, 3, 4 show biotypes Gli-A1f + Gli-A2f, Gli-A1f + Gli-A2a, Gli-A1a + Gli-A2f, Gli$A 1 a+$ Gli-A2a, respectively (only four biotypes of six for this cultivar are shown); b, Maris-Beacon (UK) - lanes 1, 2, 3 show biotypes Gli-B1g + Gli$B 2 l$, Gli-B1f + Gli-A2l, Gli-B1f + Gli-B2g, respectively (three biotypes of four for this cultivar are shown); c, Dzerdanka (Croatia) - lanes 1, 2, 3 show biotypes Gli-D1k + Gli-D2m, Gli-D1k + Gli$D 2 a$, Gli-D1a + Gli-D2a, respectively (three biotypes of eight are shown); d, Etruria (Italy) - two biotypes differing at the Gli-A3 locus are shown (arrow); e, Tselinogradka (Russia) - four biotypes differing at the Gli-A3 and Gli-B3 loci are shown (arrows). Blocks of gliadin electrophoretic bands controlled by corresponding Gli alleles are shown schematically. admixtures of foreign genotypes present in grain samples. Besides, it is possible to identify gliadin genotypes which compose a non-uniform cultivar. In our opinion, the phenomenon of the officially registered but non-uniform cultivars has not yet been studied adequately.

In this work, we analyzed the frequency of occurrence of cultivars composed of authentic biotypes in contrast to the presence of foreign genotypes (admixtures) in grain samples of the T. aestivum cultivars grown worldwide and bred during the 20th century. Analysis of frequencies of natural biotypes in 22 grain samples of the Russian spring cultivar Saratovskaya-29 permitted confirmation that biotypes of a nonuniform cultivar might differ strongly in their characters, thus permitting study of the evolution of genotypic diversity of such a cultivar in different growth conditions.

\section{Materials and methods}

\subsection{Grain materials}

Almost all grain samples of common wheat ( $T$. aestivum L.) were obtained (0.1-0.5 kg of seeds per sample) from genetic and/or breeding laboratories, mainly from the countries of origin of cultivars studied.

Gliadin alleles for more than 1000 world-wide cultivars, lines, accessions and landraces were identified earlier (Table S1 in Metakovsky et al., 2018). In the present work, only 754 officially registered cultivars (not breeders' lines, nor unregistered genotypes) from this list were considered.

The internet site (wheatpedigree.net) was used to identify the country of origin, year of release and pedigree of cultivars. Also, we followed the spelling of names of cultivars accepted in this site.

\subsection{Methods}

For most grain samples, at least 10-12 random individual seeds per cultivar were studied. In French and Spanish, and in some Russian cultivars, four, and up to 100 seeds were analyzed, respectively. Differences between the electrophoregrams of single seeds of the same cultivar were interpreted in accordance with known genetic control of gliadin bands composing allelic variants of blocks (Metakovsky et al., 2018).

In the study of frequencies of biotypes of the cultivar Saratovskaya29 , at least 150 single seeds randomly selected from a grain sample (in spike samples, one seed per plant) were analyzed electrophoretically. To compare the agricultural and quality characters of biotypes of this cultivar, half grains were characterized for biotype and the corresponding half grain was grown up to produce more grain of each biotype. In total, 26-48 individuals per biotype were evaluated, each one from a half-seed.

To compare the distribution of biotypes with respect to seed size, 100-200 visually smallest and 100-200 biggest seeds from a grain sample were selected and studied for biotype identity.

The significance of the difference of occurrence of biotypes in two samples of Saratovskaya-29 was checked by the $\chi^{2}$ test with one degree of freedom (Rana and Singhal, 2015). Common $\chi^{2}$ and Student tests were also used where necessary.

\section{Results}

\subsection{Authentic biotypes in a non-uniform cultivar may differ at any Gli locus}

Seed-by-seed analysis of a grain sample permits the discovery of an otherwise hidden non-uniformity of the cultivar under study. The cultivar might be composed of two or more homozygous genotypes differing by alleles at one or more Gli loci which arose from the cross as performed by the breeder. There were cultivars composed of biotypes (distinct genotypes) that differed by alleles at any one of the six major Gli loci (Figs. 1, 2; Figs. S1, S2). Biotypes might also differ by the presence or absence of single $\omega$-gliadins (Fig. 1d, e; Fig. S2a) known to be encoded by the Gli-3 loci (reviewed in Metakovsky, 2015).

For a cultivar composed of several biotypes, the greatest contrast between biotypes might be a difference at two or more Gli loci simultaneously. As examples, Fig. 1 shows two biotypes of the cultivar Egret (Fig. 1a, lanes 2 and 3), two biotypes of Maris-Beacon (Fig. 1b, lanes 1 and 3) and two biotypes of Dzerdanka (Fig. 1c, lanes 1 and 3) differing by alleles at two loci simultaneously (at the Gli-A1 and Gli-A2, Gli-B1 and Gli-B2, and Gli-D1 and Gli-D2 loci, respectively). Two contrasting biotypes of the cultivar Tselinogradka, differing at the Gli-A3 and Gli-B3 loci, are shown also (Fig. 1e, for example, lanes 1 and 2). Some biotypes of the cultivar Saratovskaya-29 differed at the Gli-A1, Gli-A2 and Gli-B2 loci simultaneously (Fig. 2a, for example, Biotypes 3 and 5).

However, contrasting biotypes of a non-uniform cultivar are always linked through at least one more closely-related genotype, so that each 
a

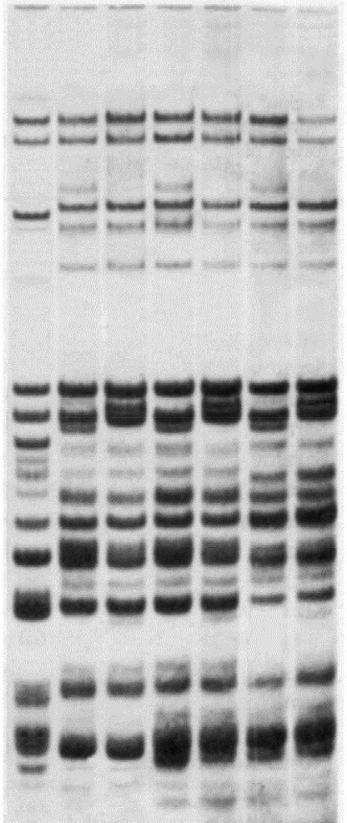

B 4322156

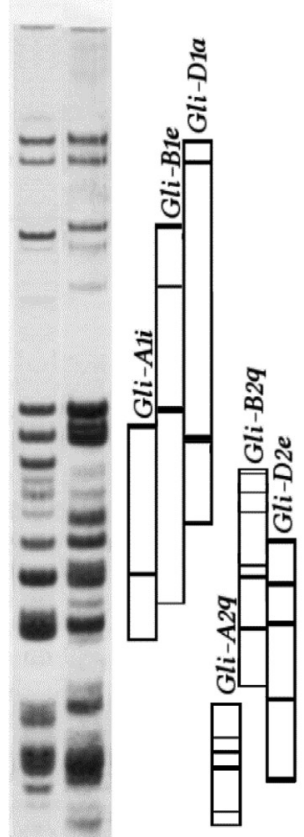

B 1

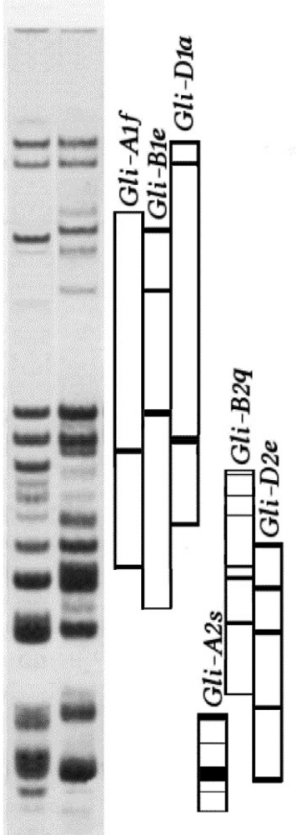

B 4

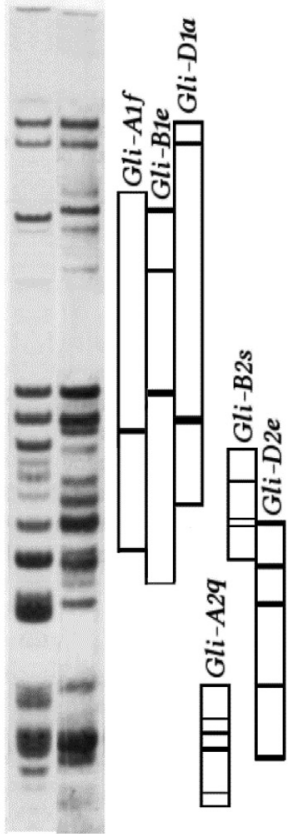

B 5

b

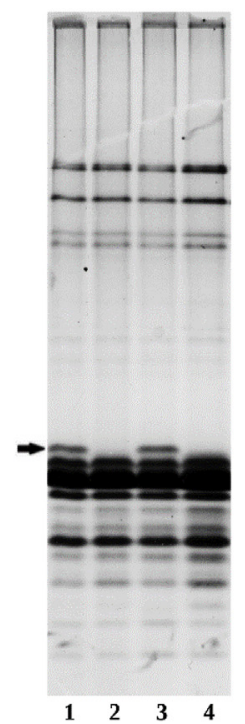

Fig. 2. Biotypes of the non-uniform cultivar Saratovskaya-29. a, Electrophoregrams of gliadin of six biotypes of Saratovskaya-29 (lanes 1-6) and of the standard cultivar Bezostaya-1 (lane B) are shown. Gliadin genotypes of six biotypes of the cultivar are: 1 - Gli-A1i, Gli-A2q, Gli-B2q; 2 - Gli-A1f, Gli-A2q, Gli-B2q; 3 - Gli-A1i, Gli-A2s, Gli-B2q; 4 - Gli-A1f, Gli-A2s, Gli-B2q; 5 - Gli-A1f, Gli-A2q, Gli-B2s; 6 - Gli-A1i, Gli-A2q, Gli-B2s. Each of the six genotypes of Saratovskaya-29 had alleles Gli$B 1 e$, Gli-D1a, and Gli-D2e. Blocks of gliadin electrophoretic bands controlled by corresponding alleles are shown schematically. b, SDS-electrophoregram of the four main biotypes (numbered 1, 2, 3, 4) of Saratovskaya-29. The difference between biotypes is shown by an arrow.

pair of them differ at one locus only. For example, the biotype of MarisBeacon (Fig. 1b, lane 2) links two contrasting biotypes (lanes 1 and 3) being different from each other at one Gli locus only (at Gli-B1, and Gli$B 2$, respectively).

\subsection{Frequency of occurrence of cultivars composed of authentic biotypes}

In total, 403 cases of two alleles at one of eight Gli loci which were considered (Gli-1, Gli-2, Gli-3) were discovered in the 756 cultivars studied. The most frequent non-uniform cultivars (composed of authentic biotypes) had two biotypes differing by alleles at one Gli locus ( $15.4 \%$ of all cultivars studied, or about $55 \%$ of all non-uniform cultivars with biotypes) (Figs. S1 and S2). About $6.8 \%$ of all cultivars were represented by four biotypes differing at two loci (for example, Fig. 1e), and $3.3 \%$ of cultivars were composed of up to eight biotypes differing at three Gli loci simultaneously (Fig. 2a). Several non-uniform cultivars were composed of many authentic biotypes, so that the most contrasting genotypes of such cultivars differed at five or six major Gli loci 
simultaneously. For example, the grain sample studied of the cultivar Omskaya-9 was composed of a number of biotypes, the most contrasting of them differed at all six major Gli loci simultaneously (alleles at the Gli-A1, Gli-B1, Gli-D1, Gli-A2, Gli-B2, Gli-D2 loci were $f, e, a, q, q$, $e$, and $b, b, b, s, b, b$, respectively (see Table S1).

In total, 233 cultivars studied were composed of authentic biotypes differing by alleles at one or more of the eight Gli loci considered. Therefore, the frequency of occurrence of biotypes in registered common wheat cultivars studied exceeded, in general, $30 \%$.

\subsection{The difference between biotypes and admixtures in grain samples}

How is it possible to distinguish authentic biotypes (true and consistent components of the cultivar) from seeds occurring occasionally (foreign genotypes) in the grain sample of a cultivar under study?

A foreign seed, in contrast to authentic biotypes, is defined as not being a genuine part of a given cultivar, aithough being found in the grain sample under study. Genotypes of foreign seeds differed in a grain sample under study and in different grain samples of the same cultivar. We considered a seed as foreign in a grain sample, first, when its genotype differed considerably (at two or more of the Gli loci simultaneously) from genotypes of other grains of the cultivar, and, second, when the Gli alleles which might be identified in this off-type seed were not present in genotypes of the respective parental cultivars (Appleyard et al., 1979; Sobko and Sozinov, 1999). This second criterion would exclude the deviating seed as coming from the original cross that produced the cultivar under study. Moreover, a seed heterozygous at a Gli locus was considered, in this work, as an admixture even if the heterozygote seed may have been produced by a cross between different biotypes of the same non-uniform cultivar.

Off-types may appear in a grain sample as a result of occasional outcrossing between wheat genotypes. For example, an off-type seed found in the grain sample of the uniform cultivar Loreto was probably a descendant of a casual cross-pollination: it was a heterozygote for the Gli-B1 locus (alleles $c+k$ ) and it carried a substitution at the Gli-D2 locus as compared with other seeds of Loreto (Fig. S3a). Two different off-type seeds in the cultivar Libellula (uniform at the Gli loci) were heterozygous at Gli-B1 and differed from the cultivar at least at the GliA1 and Gli-D1 loci (Fig. S3b).

An admixture may also appear as a result of handling with grain samples. In this case, genotypes of the cultivar and the off-type seed would differ at several Gli loci. For example, genotypes of seeds of the cultivar HY-320 (Fig. S1g, lanes 2, 3) and the seed of admixture found in the grain sample of this cultivar (lane 1) differed, at least, at four major Gli loci. Sometimes, the gliadin genotype of an admixed seed might be recognized as belonging to a well-known cultivar, whose prevalence would make it a likely seed to appear as a contaminant. For example, the genotype of the deviating seed (Fig. S1a, lane 1) found in the grain sample studied of the French cultivar Centurion (lanes 2, 3) differed from this cultivar by alleles at the Gli-A1, Gli-B2 and Gli-D2 loci, but it was identical to that of the French cultivar Festin.

As a rule, there were one or two different (Fig. S3b) off-type seeds out of ten or more seeds studied in a grain sample. In a few cases, however, seeds of admixture were present in a considerable amount. For example, in the grain sample of the old cultivar Sarrubra, there were 15 seeds of different homozygous genotypes of admixture out of 47 seeds studied (data not shown). The grain sample studied of another old cultivar, Vilmorin-27, consisted of two genotypes, in equal amounts, differing at four major Gli loci. Analysis of pedigrees in which Vilmorin-27 participated as one of parents showed that only one of these two genotypes could have transferred its alleles (Gli-B1f, Gli-A2g, Gli-B2o, Gli-D2g) into numerous descendants (data not shown) while the other genotype did not do that and was thus recognized as being due to admixture.

The frequency of cultivars having off-type seeds in their grain samples varied significantly between sets of cultivars obtained from different countries. In most of these sets, this frequency did not exceed $5 \%$ of all cultivars studied in the set, but in a few cases, nearly every second cultivar from the set contained some seed of admixture.

\subsection{Genotypes (biotypes) of a non-uniform cultivar: correspondence to pedigree and their frequency in the grain sample of the cultivar}

Authentic biotypes in any cultivar appear as a consequence of crosses of the parental genotypes performed by a breeder. Therefore, all alleles identified in all biotypes of a given non-uniform cultivar must exist in the parents mentioned in the pedigree of this cultivar.

It is possible to perform the analysis of inheritance of gliadin alleles by a daughter non-uniform cultivar only if all Gli alleles have been identified in all the cultivars that participated in the pedigree of this cultivar. In total, there were about 60 pedigrees for which all gliadin alleles were known for all cultivars in a pedigree, and the correspondence of the allelic composition of a daughter (non-uniform) and its parental cultivars has been confirmed (Table S1). For example, the nonuniform cultivar Maris-Beacon (Fig. 1b) might obtain its alleles Gli-A1 af and Gli-A2l from the cultivar Professour-Marchal, alleles Gli-B1f and Gli-B2g - from Cappelle-Desprez, and each of alleles Gli-B1g, Gli-D1b, Gli-B2l, and Gli-D2a, might be received by the cultivar Maris-Beacon from more than one of its parents (Table S1).

Two authentic biotypes differing by alleles at a Gli locus arise from a genotype heterozygous for this locus. If so, two biotypes, being a consequence of genetic segregation of this heterozygote, should occur with similar frequency in the population of seeds of a non-uniform cultivar. Indeed, out of 15 seeds of the cultivar Pernel, eight had allele Gli-D2h, and seven had Gli-D2c. There is no doubt that two biotypes of this cultivar appeared as a result of genetic segregation of an original genotype heterozygous at the Gli-D2. Analogously, in the cultivar Zagore, 11 seeds carried the allele Gli-A2p, and nine seeds had Gli-A2e. In the cultivar Zernogradka-3, there were 12 seeds with the allele Gli-B2b and 10 seeds with the Gli-B2m.

In some cases, however, one of two alleles at the same locus occurred, in the grain sample studied, much more frequently than another. For example, in several grain samples studied for the cultivar Bezostaya-1, alleles Gli-B1b and Gli-B2b occurred much more frequently than alleles Gli-B1d and Gli-B2o, respectively. In the grain sample of Bezostaya-1 studied in this work (50 seeds of the harvest in Krasnodar, 1986), the frequency of Gli-B1b and Gli-B2b reached $90 \%$ and $98 \%$, respectively.

In the cultivar Maris-Fenman, only eight seeds had the allele Gli-D2 $g$ while the Gli-D2a occurred in 52 seeds. Also, the distribution of seeds between four biotypes of the cultivar Egret differing at the Gli-A1 and Gli-A2 (Fig. 1a, lanes 1, 2, 3, 4) was 22, 12, 27, and 15 seeds, respectively. The difference between frequencies of biotypes in populations of seeds of Maris-Fenman and of Egret were statistically significant for each of these cultivars (in each case, $\mathrm{p}<0.01$ ).

These observations raise a question about the possible value (or otherwise) of the presence of biotypes and of alterations in the proportions of different biotypes in a wheat cultivar.

\subsection{Evolution of the non-uniform spring cultivar with time}

The high-quality cultivar Saratovskaya-29 was bred through the cross of two registered cultivars (Table S1) each of them originated from landraces grown in the Volga region of Russia. Since being registered in 1957, it was the best of the former USSR's spring cultivar during more than two decades and grew in enormous areas in different regions of Russia having different eco-climatic conditions (Dobrotvorskaya et al., 2004).

The cultivar Saratovskaya-29 consists of six authentic biotypes differing at three main Gli loci (numbered from 1 to 6 ). The four main Biotypes (from 1 to 4 ) have the allele Gli-B2q and differ from one another due to alleles at the Gli-A1 $(i+f)$ and $\operatorname{Gli}-A 2(q+s)$ loci. Biotypes 
$\%$

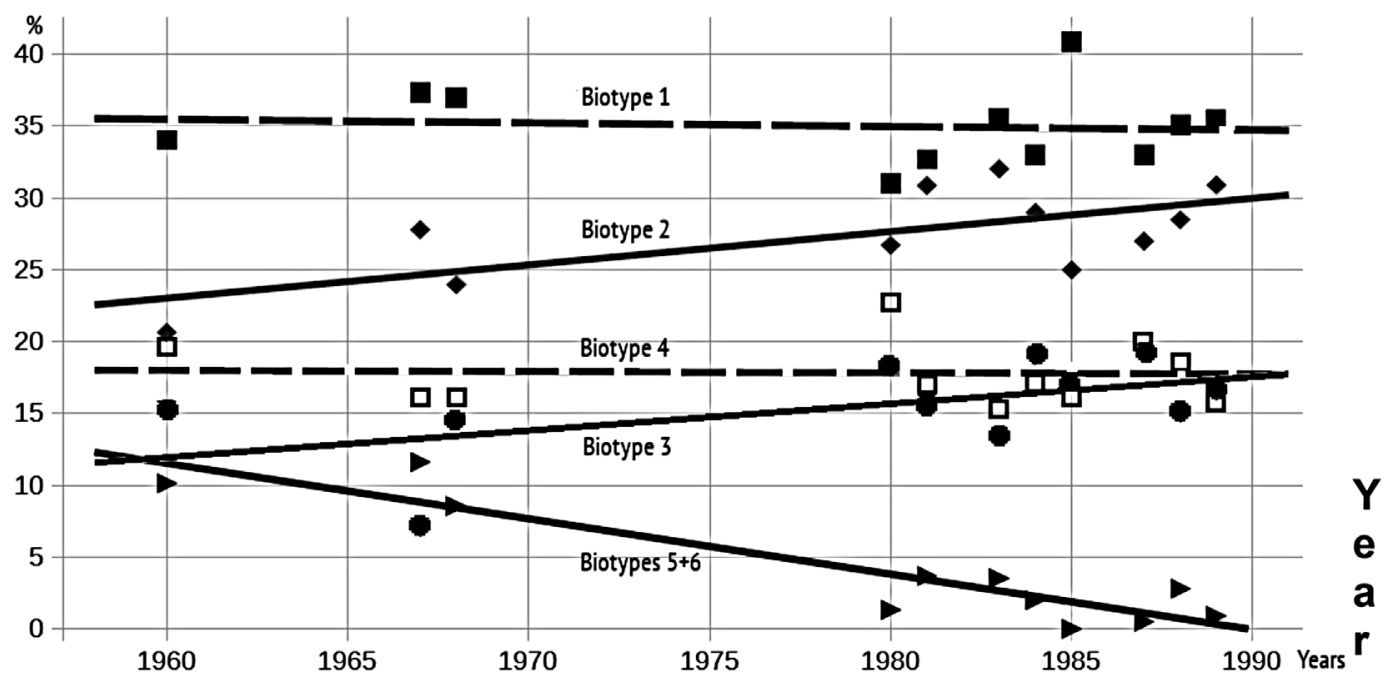

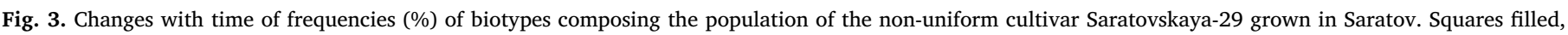
broken line, Biotype 1; Rhombus, Biotype 2; Circles, Biotype 3; Squares open, broken line, biotype 4; Triangles, sum of Biotypes 5 and 6.

5 and 6 have the allele Gli-B2s (Fig. 2a). The cultivar was found to be uniform at the Glu-1 loci (Glu-A1b, Glu-B1c, Glu-D1d), but Biotypes 1 and 3 (with the allele Gli-A1i) differed clearly from Biotypes 2 and 4 by the composition of the B-type low-molecular-weight glutenin subunits (Fig. 2b).

Temporal and spatial differences in the proportions of six biotypes in the population of this cultivar were studied.

Eleven samples came from harvests of Saratovskaya-29 grown from 1960 to 1989 in the Saratov region, native for this cultivar. The ratio of the two contrasting Biotypes 1 and 4, differing at both Gli-A1 and GliA2, did not show any temporal change during these decades (Fig. 3, broken lines), whereas some increases in the frequencies of Biotypes 2 and 3 were observed. At the same time, the joint frequency of the two biotypes with the allele Gli-B2s decreased from 10\% in 1960 to less than $4 \%$ in the 1980s (Fig. 3).

In the study of 11 samples of Saratovskaya-29 from other regions (from a few to ten and more years of reproduction in a given region), some differences were discovered between the frequencies of the same biotype in the population of the cultivar grown in Saratov and in an alien region. For statistics, the frequency of a biotype in an alien region was compared, first, with the average value of the same biotype between all samples of Saratovskaya-29 grown in Saratov, and second, with the extreme frequency of this biotype among Saratov's samples.

Thirteen cases of the significant difference were observed between the average frequency of a biotype in samples from Saratov and the same biotype in a sample of this cultivar grown in another region (Table 1). Moreover, a significant difference was observed between the frequency of Biotype 2 in the sample from Alma-Ata (south Kazakhstan), of Biotype 4 in Barnaul (west Siberia), of Biotypes 3 and 4 in Yakutsk (east Siberia), of Biotypes $5+6$ in Kharkov (Ukraine), and samples from Saratov having, in one of 11 harvests studied, an extreme value of the frequency of the corresponding biotype (Table 1).

In general, in the alien regions, a slight increase of the frequency of the Biotype 1 and a drop of the proportion of Biotype 4 was observed (Table 1).

\subsection{Biotypes of the cultivar Saratovskaya-29 differ in agricultural} characters including dough quality

Four biotypes (from 1 to 4) of the cultivar Saratovskaya-29 (Fig. 2a) differed in some indices of quality: the level of dough extensibility in four biotypes was not identical $(p<0.025)$ being higher in biotypes with Gli-A1i (Biotypes 1 and 3) as compared with two other biotypes ( $\mathrm{p}<0.01$ ). In addition, Biotype 4 also demonstrated lower figures of dough resistance and gluten content (Table 2).

Surprisingly, biotypes of Saratovskaya-29 differed in two other agriculturally important characteristics not related to dough properties. For example, Biotype 4 had higher average thousand-kernel mass and mass of seeds per spike (in both cases, $\mathrm{p}<0.05$ ) as compared with any one of other three biotypes (Table 2). Differences between Biotypes 1 and 3 in the mass of seeds per spike were also statistically significant $(\mathrm{p}<0.05)$.

In addition, the frequencies of the four main biotypes were compared between two groups of grains from the same sample, the smallest ones (the average weight of 1000 grains was $23.94 \mathrm{~g}$ ) and of the biggest ones (49.94 g) selected from seven grain samples, from Saratov (1981, 1984), Omsk (1982, 1984), Krasnoyarsk, Shortandy and Yakutsk (about these samples, see Table 1). It was discovered that the smallest seeds had a relatively higher frequency of Biotype 1, and the biggest seeds had more of Biotype 4. Due to this disproportionate distribution, the difference in the distribution of biotypes in the two groups of seeds of contrasting size, in the average of seven samples studied, was highly significant $(\mathrm{p}<0.01)$. The difference between the smallest and the biggest seeds was observed in each grain sample of Saratovskaya-29 (Table S2).

\subsection{Variations in biotype structure may determine the agricultural and quality indices of a cultivar}

To obtain material for analyses of grain quality for Saratovskaya-29 grown in different eco-climatic conditions, five grain samples $(0.5 \mathrm{~kg})$ of this cultivar which had been growing during at least ten recent years in different regions, of Novosibirsk, Omsk, Shortandy, Ust-Abakan and Yakutsk (see footnotes of Table 1 for geographic location of these regions) were grown once in Novosibirsk. Grains of this harvest of five variants of the same cultivar were compared for their dough quality.

Essential differences were observed between five variants of the same cultivar. For example, the dough resistance and the dough extensibility were obviously not identical for samples of Saratovskaya-29 grown before in different regions. The strongest difference was observed between the sample from Yakutsk and other regions: the dough of Yakutsk's Saratovskaya-29 was stronger and had low extensibility (Table 3). The peculiarity of this dough might be caused by the nearly complete disappearance, from the population of grains in Saratovskaya- 
Table 1

Frequencies (\%) of biotypes in the population of the non-uniform cultivar Saratovskaya-29 grown in different regions (in total, 2173 single seeds were studied).

\begin{tabular}{|c|c|c|c|c|c|c|c|}
\hline \multirow[t]{2}{*}{ Region of growing } & \multirow[t]{2}{*}{ Year } & \multirow[t]{2}{*}{ Number of grains ${ }^{1}$} & \multicolumn{5}{|c|}{ Frequencies of biotypes shown in Fig. 2c } \\
\hline & & & 1 & 2 & 3 & 4 & $5+6$ \\
\hline Alma-Ata ${ }^{2}$ & 1984 & 168 & 35.71 & $48.21^{* *}$ & $5.95^{*}$ & $9.52 *$ & 0.60 \\
\hline Shortandy ${ }^{3}$ & 1984 & 236 & 33.05 & 30.51 & 18.64 & 16.10 & 1.27 \\
\hline Kharkov ${ }^{4}$ & 1978 & 170 & 34.12 & 22.94 & $7.65^{*}$ & $11.18^{*}$ & $24.12^{* *}$ \\
\hline Barnaul $^{5}$ & 1977 & 168 & 36.31 & 34.52 & $25.00^{*}$ & $4.17^{* * *}$ & 0.00 \\
\hline Novosibirsk ${ }^{5}$ & 1985 & 341 & $43.40^{*}$ & 24.93 & 13.78 & 12.32 & 5.58 \\
\hline Omsk 5,6 & 1965 & 192 & 39.68 & 27.08 & 14.06 & 19.27 & 0.00 \\
\hline Omsk ${ }^{5}$ & 1982 & 181 & $48.62^{*}$ & $18.23^{*}$ & 18.23 & $11.05^{*}$ & 3.87 \\
\hline Omsk $^{5}$ & 1984 & 158 & $46.84^{*}$ & 20.89 & 17.09 & $10.76^{*}$ & 4.43 \\
\hline Ust-Abakan ${ }^{5}$ & 1984 & 207 & 38.16 & 23.67 & 16.43 & 13.53 & 8.21 \\
\hline Krasnoyarsk ${ }^{7}$ & 1984 & 152 & 34.87 & 29.61 & 16.45 & 12.50 & 6.58 \\
\hline Yakutsk $^{7}$ & 1983 & 200 & $49.00^{*}$ & $38.50^{*}$ & $1.00^{* *}$ & $7.50^{* * *}$ & 4.00 \\
\hline \multicolumn{3}{|l|}{ Average (Saratov) } & 35.07 & 26.87 & 15.77 & 18.26 & 4.05 \\
\hline \multicolumn{3}{|c|}{ Extreme values for Saratov } & $31.0-40.9$ & $19.9-32.0$ & $7.1-19.0$ & $15.5-22.8$ & $0.0-11.6$ \\
\hline
\end{tabular}

1 Number of grains studied. Admixtures (occurred with the frequency, in different samples, from zero up to $12 \%$ ) were not considered.

2 Former USSR, south Kazakhstan.

3 Former USSR, north Kazakhstan.

4 Former USSR, Ukraine.

5 Russia, west Siberia.

6 Elite spikes.

7 Russia, east Siberia.

*The frequency differed significantly $(\mathrm{p}<0.05)$ from the corresponding average value observed for harvests in Saratov.

**The frequency differed significantly $(\mathrm{p}<0.05)$ from the corresponding extreme value observed in one of harvests in Saratov.

Table 2

Agricultural and quality indices of four biotypes of Saratovskaya-29.

\begin{tabular}{|c|c|c|c|c|}
\hline Biotype $^{\text {a }}$ & 1 & 2 & 3 & 4 \\
\hline Mass 1000 grains $^{\mathrm{b}}, \mathrm{g}$ & $24.53 \pm 0.29$ & $23.82 \pm 0.29$ & $23.53 \pm 0.53$ & $25.81 \pm 0.36$ \\
\hline Mass seeds/spike ${ }^{\mathrm{b}}, \mathrm{g}$ & $0.40 \pm 0.02$ & $0.38 \pm 0.02$ & $0.35 \pm 0.02$ & $0.45 \pm 0.02$ \\
\hline Gluten, \% & 30.1 & 28.8 & 29.2 & 27.2 \\
\hline Particle size, mkm & 23.8 & 22.2 & 22.8 & 23.2 \\
\hline Dough resistance, a.u. & 502 & 503 & 488 & 445 \\
\hline Dough extensibility, mm & 251 & 210 & 257 & 202 \\
\hline Dough breackdown, f.u. & 20 & 40 & 20 & 30 \\
\hline Loaf volume, $\mathrm{ml}$ & 960 & 975 & 950 & 975 \\
\hline
\end{tabular}

a Biotypes were numbered in accordance with Fig. 2.

b Each biotype was represented by 26-48 lines.

Table 3

The quality indices of variants of the cultivar Saratovskaya-29 grown at least during 10 years in different regions (the last harvest of all five variants was in Novosibirsk).

\begin{tabular}{llllll}
\hline Regions $^{\text {a }}$ & 1 & 2 & 3 & 4 & 5 \\
\hline Gluten, \% & 28.1 & 29.4 & 29.4 & 26.4 & 26.0 \\
Particle size, mkm & 23.0 & 21.6 & 21.5 & 24.1 & 23.9 \\
Dough resistance, a.u. & 357 & 363 & 397 & 300 & 413 \\
Dough extensibility, mm & 255 & 226 & 223 & 167 & 153
\end{tabular}

a Regions: 1 - Novosibirsk, 2 - Omsk, 3 - Shortandy, 4 - Ust-Abakan, 5 Yakutsk (see Table 4 for geography).

29 grown in Yakutsk, of the Biotype 3 (Table 1) having a good extensibility (Table 2).

\section{Discussion}

Wheat is a self-pollinated species, therefore each locus (including the Gli loci) in a given cultivar should occur (theoretically) in a homozygous state. A gliadin electrophoregram (acid buffer) of a cultivar is represented by about 20 clear bands of different mobility and intensity (Figs. 1, 2a; Figs. S1, S2). However, it was noticed long ago that gliadin extracted from the flour of some cultivars gave electrophoregrams full of weaker bands, as if the gliadin in this flour was produced by heterozygotes at the Gli loci (Wrigley and Baxter, 1974). The explanation of this phenomenon was found in the non-uniformity of some cultivars. Indeed, the simultaneous presence, in the electrophoregram of the flour, of all gliadin bands encoded by different alleles at one Gli locus may make the resulting electrophoregram full of many weaker bands.

The existence, in some wheat cultivars, of biotypes distinct in alleles at the Gli loci was reported earlier (reviewed in Metakovsky, 2015). In this work, it was calculated that about $30 \%$ of world-wide common wheat cultivars are composed of authentic biotypes differing at one or more Gli loci.

The intra-varietal non-uniformity of wheat cultivars may be revealed using other genetic markers. The quota of cultivars non-uniform for the Glu-1 loci was about $10-20 \%$ in sets of cultivars bred in Australia, Canada, China, Italy, USA, former USSR, former Yugoslavia, and in a world-wide collection of cultivars (calculated from published data and reviewed in Metakovsky, 2015). Many cultivars (70\% of winter and $43 \%$ of spring wheats) bred in the former USSR were nonuniform for isozymes of $\alpha$-amylase (Illichevsky et al., 1992). Even lines of the variety Chinese-Spring differed by allelic variants of the Gpi-1 locus (Chojecki et al., 1983).

It is necessary to emphasize that the uniformity of a cultivar at the Gli loci does not guarantee the uniformity of the cultivar. Moreover, it is plausible to suggest that intra-varietal non-uniformity is widely spread throughout wheat germplasm; so that a number of cultivars uniform in 
gliadin would be non-uniform based on the analysis of any other genetic marker. Indeed, in Ukraine, $45 \%$ of winter wheat cultivars grown in 1999 were non-uniform in gliadin, but some cultivars uniform in gliadin were non-uniform when studied using polymorphism at the Glu1 loci for the subunits of glutenin (Sobko and Sozinov, 1999). Comparison of the published results of analyses of genotypes of Bulgarian cultivars using microsatellite DNA markers (Landjeva et al., 2006) and gliadin polymorphism (Table S1 in Metakovsky et al., 2018) showed that ten of 29 cultivars identical in the two studies were non-uniform in microsatellite analysis and uniform in gliadin alleles, and four cultivars uniform in microsatellites were non-uniform in gliadin.

In our opinion, the phenomenon of the non-uniformity of wheat cultivars has still not been properly considered, nor has it received enough attention. For example, as a rule, a possible heterogeneity of seed material used for analysis is not routinely considered, in many cases, in studies on wheat DNA. In one of a very few examples when non-uniformity was taken into account, it was discovered that about $74 \%$ of Bulgarian cultivars were non-uniform, at least, at one of the 19 microsatellites used (Landjeva et al., 2006). This level exceeds that we found in Bulgarian germplasm using gliadin polymorphism (54\%) (data not shown).

Apparently, the intra-varietal non-uniformity of common wheat cultivars is not accidental in wheat germplasm, and this phenomenon needs to be explained. What is the importance of the non-uniformity of cultivars?

First, the presence of several related but different genotypes adds some polymorphism to a given cultivar and thereby may increase its adaptivity and plasticity. Indeed, samples of a non-uniform cultivar may differ significantly by the proportion of its biotypes (genotypes) (Table 1). We suggest that spatial variations in the frequency of biotypes of the non-uniform cultivar Saratovskaya-29 may be caused by adaptation of this cultivar (as a population of different genotypes) to given eco-climatic conditions. A strong geographic differentiation of the polymorphism at the Gli and other loci of wheat cultivars was claimed earlier (Metakovsky et al., 2019).

Second, It was shown earlier that some Australian cultivars composed of biotypes differed by alleles at the Glu-1 loci and by dough quality (Lawrence et al., 1987; Gupta and Shepherd, 1988). In this work, we documented the difference between four major biotypes for the non-uniform cultivar Saratovskaya-29 in several agriculturally important parameters including thousand kernel mass, gluten content and dough elasticity (Table 2).

It seems logical to suggest that changes in the frequency of biotypes in different conditions of growth may influence the quality of a given non-uniform cultivar as a whole. Indeed, the disappearance of one of the biotypes (Biotype 3) of the cultivar Saratovskaya-29 grown in the severe eco-climatic conditions of the East Siberia (Yakutsk) caused a considerable change in the dough quality of the cultivar (Table 3).

Third, the intra-varietal non-uniformity revealed using polymorphism of any genetic markers (of storage proteins, enzymes, DNA markers) should be assumed as an indication on the probable nonuniformity at other loci. Moreover, a cultivar found to be non-uniform, for example, at one Gli locus, may be composed, in fact, of a complex mixture of several (or many) authentic biotypes hidden under the mask of morphological uniformity. These biotypes may have different agricultural and biological characteristics. Indeed, electrophoregrams of the main four biotypes of Saratovskaya-29 differed in the presence or absence only of a few gliadin bands (Fig. 2a). This small difference between sets of gliadin polypeptides produced by four biotypes may hardly explain all observed disproportions found in agriculturally important indices between these biotypes, for example, in thousand-kernel mass. Obviously, the biotypic structure of the cultivar Saratovskaya-29 may be more complex than is represented by only four major biotypes differing at two Gli loci.

In contrast to the unintentional lack of uniformity described above, advantages have been produced by breeding "multi-line" cultivars, containing a mix of similar genotypes that differ in their tolerance to fungal infection, whereby an attack by one race of rust (or similar source of infection) affects only a part of the range of multi-line genotypes (Marshall and Pryor, 1978).

Knowledge of the component composition of gliadin blocks provides a basis, not only to distinguish between authentic biotypes of a cultivar, but also to differentiate them from admixtures of foreign genotypes, including seeds heterozygous at the Gli loci. Our analysis of some lines of the cultivar Moskovskaya-35, which differed from the main type of the cultivar in flour quality (Nettevich et al., 1981) showed that these off-type lines were obtained, in fact, from admixtures of foreign genotypes (Metakovsky, 2015). On the other hand, one of the genotypes of the cultivar Rusalka was assumed to be an "admixture" of cross-pollination origin (Spetsov et al., 1997), although this genotype was probably one of eight authentic biotypes of this cultivar differing at the three Gli loci (Table S1 in Metakovsky et al., 2018).

Ten of 205 seeds studied representing nine cultivars were assumed to be a result of undesirable cross-pollination (Pogna et al., 1986). It is reported that some genotypes of T. aestivum show an increased inclination to cross-pollination (Kozub et al., 2008). Moreover, it was suggested that the Ukrainian cultivar Illichevka had lost its quality and was removed from production because of its high inclination to crosspollination (Kolyichii and Sozinov, 2000).

The presence of off-type seeds in a wheat sample may lead to incorrect interpretations of results in scientific experimentation. A significant case of "damage" caused by admixtures to experimental work was provided in studies of somaclonal variation in common wheat. The published gliadin electrophoregrams of in-vitro produced genotypes strongly differed from control ones. Our analysis showed that these offtype genotypes were, in fact, either descendants of an occasional outcrossing of the initial genotypes, or admixtures present in the grain samples used in the experiment (Metakovsky and Sozinov, 1990).

\section{Conclusion}

Intra-varietal non-uniformity is widely spread across registered wheat cultivars, thereby violating the demand of the DUS rule for intravarietal uniformity, but this phenomenon does not attract much attention in studies on common wheat. The non-uniformity discovered at any locus indicates that the cultivar may be represented by a mixture of hidden biotypes that also differ at other loci, possibly related to important wheat characteristics including grain quality. Grain samples of the cultivar Saratovskaya-29 grown in different regions, differed significantly in biotype proportions, suggesting that there is value in multiple biotypes for the adaptation of a non-uniform cultivar to given eco-climatic conditions of growth. Changes of frequencies with time for authentic biotypes differing in their quality indices may alter some characteristics for the cultivar as a whole. The presence in a wheat sample under study of any intra-varietal non-uniformity (authentic biotypes or even a small level of admixtures) may lead to the wrong interpretation of results in a scientific experiment.

\section{Acknowledgments}

The authors thank Dr S.Davydov (Institute of the Agriculture of South-East, Russia) for his help in the development and preliminary analysis of lines of the cultivar Saratovskaya-29. This research did not receive any specific grant from funding agencies in the public, commercial, or not-for-profit sectores.

\section{Appendix A. Supplementary data}

Supplementary data to this article can be found online at https:// doi.org/10.1016/j.jcs.2019.102813. 


\section{Conflicts of interest}

\section{The authors declare that they have no conflict of interest.}

\section{References}

Appleyard, D.B., McCausland, J., Wrigley, C.W., 1979. Checking of identity and origin of off-types in the propagation of pedigreed wheat seed. Seed Sci. Technol. 7, 459-466.

Chojecki, A.J.S., Gale, M.D., Holt, L.M., Payne, P.I., 1983. The intra-chromosomal mapping of a glucose phosphate isomerase structural gene using allelic variation among stocks of Chinese Spring wheat. Genet. Res. 41, 221-226.

Cooke, R.J., 1995. The reasons for variety identification. In: Wrigley, C.W. (Ed.), Identification of Food-Grain Varieties. AACC, St.Paul, MN, pp. 1-17.

Cooke, R.J., Wrigley, C.W., 2004. Variety registration and breeders' rights. In: Encyclopedia of Grain Science, vol. 3. Elsevier Ltd, Oxford, UK, pp. 314-321.

Dobrotvorskaya, T.V., Martynov, S.P., Pukhalskyi, V.A., 2004. Trends in genetic diversity change of spring bread wheat cultivars released in Russia in 1929-2003. Russ. J. Genet. 40, 1545-1557 (in Russian).

Gupta, R.B., Shepherd, K.W., 1988. Low-molecular-weight glutenin subunits in wheat: their variation, inheritance and association with bread-making quality. In: In: Miller, T.E., Koebner, R.M.D. (Eds.), Proc. 7th Intern. Wheat Genetics Symp., vol. 2. IPSR, Cambridge, UK, pp. 943-949.

Illichevsky, N.N., Upelniek, V.P., Metakovsky, E.V., 1992. Alleles of genes encoding $\alpha$ amylase in common wheat cultivars bred in the USSR and differing in grain quality Russ. J. Genet. 28 (11), 97-110 (in Russian).

Kolyichii, V.T., Sozinov, A.A., 2000. Influence of natural selection on the frequency of gliadin-coding loci, and their association in an artificially produced hybrid population of winter wheat. Cytol. Genet. 34, 32-38 (in Russian).

Kozub, N.A., Sozinov, I.A., Sozinov, A.A., 2008. Dependence of the level of cross-pollination from genotype in common wheat. Cytol. Genet. 42, 87-93 (in Russian).

Landjeva, S., Korzun, V., Ganeva, G., 2006. Evaluation of genetic diversity among Bulgarian winter wheat (Triticum aestivum L.) varieties during the period 1925-2003 using microsatellites. Genet. Resour. Crop Evol. 53, 1605-1614.

Law, J.R., Donini, P., Koebner, R.M.D., Reeves, J.C., Cooke, R.J., 1998. DNA profiling and plant variety registration. III. The statistical assessment of distinctness in wheat using amplified fragment length polymorphisms. Euphytica 102, 335-342.

Lawrence, G.J., Moss, H.J., Shepherd, K.W., Wrigley, C.W., 1987. Dough quality of biotypes of eleven Australian wheat cultivars that differ in high-molecular-weight glutenin subunit composition. J. Cereal Sci. 6, 99-101.

Marshall, D.R., Pryor, A.J., 1978. Multiline varieties and disease control. 1. The "dirty crop" approach with each component carrying a unique single resistance gene. Theor. Appl. Genet. 51, 177-184.

Metakovsky, E.V., 2015. Wheat storage proteins: genes, inheritance, variability, mutations, phylogeny, seed production, flour quality. Lambert Acad. Publ., Saarbrücken,
Deutschland 338 pp. (in Russian, English summary).

Metakovsky, E.V., Sozinov, A.A., 1990. Genetics of gliadin proteins and the problems of interpreting results obtained with somaclonal variation in wheat. In: Bajaj, Y.P.S. (Ed.), Biotechnology in Agriculture and Forestry, 13 (Wheat, pp. 526-537.

Metakovsky, E.V., Chernakov, V.M., Upelniek, V.P., Redaelli, R., Dardavet, M., Branlard, G., Pogna, N.E., 1996. Minor $\omega$-gliadin-coding loci on chromosome 1A of common wheat: a revision. J. Genet. Breed. 50, 277-286.

Metakovsky, E.V., Melnik, V.A., Rodriguez-Quijano, M., Upelniek, V.P., Carrillo, J.M., 2018. A catalogue of gliadin alleles: polymorphism of 20th-century common wheat germplasm. Crop J. 6, 628-641.

Metakovsky, E.V., Melnik, V.A., Pascual, L., Wrigley, C.W., 2019. Gliadin genotypes worldwide for spring wheats (Triticum aestivum L). 2. Strong differentiation of polymorphism between countries and regions of origin. J. Cereal Sci (in press).

Nettevich, E.D., Berkutova, N.S., Pogorelova, L.G., 1981. Intravarietal grain quality polymorphism of the spring wheat cultivar Moskovskaya 35. Dokl. VASKhNIL 2, 4-6 (in Russian).

Pogna, N.E., Peruffo, A.D.B., Boggini, G., Corbellini, M., 1982. Analysis of wheat varieties y gliadin electrophoregrams. II. Nature, origin and quality of biotypes present in six Italian common wheat varieties. Genet. Agrar. 6, 143-154.

Pogna, N.E., Borghi, B., Mellini, F., Peruffo, A.D.B., Nash, R.J., 1986. Electrophoresis of gliadins for estimating the genetic purity in hybrid wheat seed production. Genet. Agrar. 40, 205-212.

Rana, R., Singhal, R., 2015. Chi-square test and its application in hypothesis testing. J. Pract. Cardiovasc. Sci. 1, 69-71.

Sobko, T.A., Poperelya, F.A., 1986. Frequencies of alleles at the gliadin-coding loci in common winter wheat cultivar. Visnik Silskogosp. Nauki (in Ukrainian) 5, 84-87.

Sobko, T.A., Sozinov, A.A., 1999. Analysis of genotypes of common winter wheat cultivars grown in Ukraine using genetic markers. Cytol. Genet. 33, 30-41.

Sozinov, A.A., Poperelya, F.A., 1980. Genetic classification of prolamins and its use for plant breeding. Annu. Technol. Agric. 29, 229-245.

Spetsov, P., Mingeot, D., Jacquemin, J.M., Samardjieva, K., Marinova, E., 1997. Transfer of powdery mildew resistance from Aegilops variabilis into bread wheat. Euphytica 93, 49-54.

Uthayakumaran, S., Wrigley, C.W., Batey, I.L., Bushuk, W., Lookhart, G.L., 2006. Genotype identification. In: Wrigley, C., Békés, F., Bushuk, W. (Eds.), Gliadin and Glutenin. The Unique Balance of Wheat Quality. AACC International, pp. 307-331.

Wrigley, C.W., Baxter, R.I., 1974. Identification of Australian wheat cultivars by laboratory procedures: grain samples containing a mixture of cultivars. Aust. J. Exp. Agric. Anim. Husb. 14, 805-810.

Wrigley, C.W., Shepherd, K.W., 1974. Identification of Australian wheat cultivars by laboratory procedures: examination of pure samples of grain. Aust. J. Exp. Agric. Anim. Husb. 14, 796-804.

Wrigley, C.W., Autran, J.C., Bushuk, W., 1982. Identification of cereal varieties by gel electrophoresis of the grain proteins. Adv. Cereal Sci. Technol. 5, 211-259. 